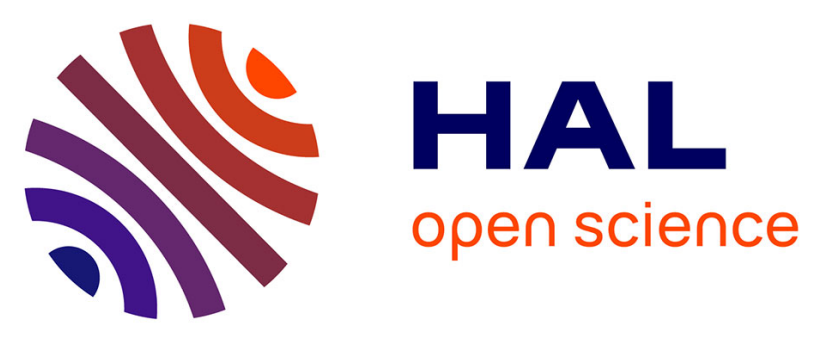

\title{
Post Processing Dispersion Trimming for On-Chip Mid-Infrared Supercontinuum Generation
}

Alberto Della Torre, Milan Sinobad, Barry Luther-Davis, Pan Ma, Stephen

Madden, Sukanta Debbarma, Khu Vu, David J. Moss, Arnan Mitchell, Jean-Michel Hartmann, et al.

\section{To cite this version:}

Alberto Della Torre, Milan Sinobad, Barry Luther-Davis, Pan Ma, Stephen Madden, et al.. Post Processing Dispersion Trimming for On-Chip Mid-Infrared Supercontinuum Generation. CLEO Europe, Jun 2019, Munich, Germany. 10.1109/cleoe-eqec.2019.8872153 . hal-02566006

\section{HAL Id: hal-02566006 https://hal.science/hal-02566006}

Submitted on 12 May 2020

HAL is a multi-disciplinary open access archive for the deposit and dissemination of scientific research documents, whether they are published or not. The documents may come from teaching and research institutions in France or abroad, or from public or private research centers.
L'archive ouverte pluridisciplinaire HAL, est destinée au dépôt et à la diffusion de documents scientifiques de niveau recherche, publiés ou non, émanant des établissements d'enseignement et de recherche français ou étrangers, des laboratoires publics ou privés. 


\title{
Post processing dispersion trimming for on-chip mid-infrared supercontinuum generation
}

\author{
Alberto Della Torre ${ }^{* 1}$, Milan Sinobad ${ }^{1,2}$, Barry Luther-Davis ${ }^{3}$, Pan Ma ${ }^{3}$, Stephen Madden ${ }^{3}$, Sukanta Debbarma ${ }^{3}, K_{h u}$ Vu ${ }^{3}$, \\ David J. Moss ${ }^{4}$, Arnan Mitchell ${ }^{2}$, Jean-Michel Hartmann ${ }^{5}$, Jean-Marc Fedeli ${ }^{5}$, Christelle Monat ${ }^{1}$, Christian Grillet ${ }^{1}$ \\ ${ }^{1}$ Université de Lyon, Institut des Nanotechnologies de Lyon (INL), 69131 Ecully, France ; ${ }^{2}$ School of Engineering, RMIT \\ University, Melbourne, VIC 3001, Australia; ${ }^{3}$ Laser Physics Center, Australian National University, Canberra, ACT 0100 , \\ Australia; ${ }^{4}$ Centre for Microphotonics, Swinburne University of Technology, Hawthorn, VIC 3122, Australia; ${ }^{5}$ Université \\ Grenoble Alpes,CEA-Leti, 38054 Grenoble Cedex 9, France; *e-mail : alberto.della-torre@ec-lyon.fr
}

\begin{abstract}
We report anomalous to normal dispersion shift of a mid-infrared supercontinuum in a hybrid chalcogenide/silicon-germanium waveguide. We show that the waveguide's dispersion can be precisely tuned by controlling the thickness of a chalcogenide cladding layer. (c) 2019 The Authors
\end{abstract}

On-chip mid-infrared (3-20 $\mu \mathrm{m})$ supercontinuum (SC) generation has potential applications in many different fields such as bio imaging, environmental sensors and security [1]. Recently, the wide transparency window from 3 to $15 \mu \mathrm{m}$ and CMOS compatibility of germanium, along with the prediction of great nonlinear properties [2-3], have attracted a growing interest toward germanium-based platforms and octave spanning SC generation up to $8.5 \mu \mathrm{m}$ has been demonstrated in a silicon-germanium on silicon waveguide [4]. The spectral properties and the coherence of the generated SC strongly depend on the waveguide's dispersion profile and a careful design of the group velocity dispersion is required. However, the actual dispersion of the waveguide produced by fabrication is often different from the target one, as it is sensitive to fabrication inaccuracies, surface contamination and the presence of defects. Post-process tuning mechanisms are therefore of great interest to adjust or correct a posteriori the waveguide dispersion to match the target value. Several approaches have been proposed for post-process tuning of optical properties in optical fibers [5-6] and photonic crystals [7-10]. However, the restricted number of design parameters makes post-process dispersion control of waveguides trickier. Here, we show that it is possible to fine tune the dispersion profile a posteriori by adding a chalcogenide cladding layer on top of a highly nonlinear silicon-germanium on silicon waveguide, introducing a simple post processing tool to control the supercontinuum dynamics and its properties.

SC generation was first achieved in a $7 \mathrm{~cm}$ long $3.75 \times 2.7 \mu \mathrm{m}^{2}$ cross-section air clad waveguide. The waveguide, operating in TE single mode, was pumped in anomalous dispersion with $\sim 200 \mathrm{fs}$ pulses at $4 \mu \mathrm{m}$ and $63 \mathrm{MHz}$ repetition rate. The resulting SC, spanning from 2.63 up to $6.18 \mu \mathrm{m}$, shows asymmetric profile and uneven amplitude across the spectrum, both typical of SC generation in the anomalous dispersion regime. A $1.26 \mu \mathrm{m}$ thick coating layer of chalcogenide $\mathrm{Ge}_{11.5} \mathrm{As}_{24} \mathrm{Se}_{64.5}$ was then deposited by thermal vapor deposition. The chalcogenide clad waveguide was pumped with pulses with the same parameters as before at $4.15 \mu \mathrm{m}$. A narrower and smoother spectrum (with a $-30 \mathrm{~dB}$ bandwidth extending from 3.1 to $5.5 \mu \mathrm{m}$ ), typical of SC generation in normal dispersion regime, was obtained. The SC generation process was simulated by numerically solving the nonlinear Schrödinger equation using the split-step Fourier method, obtaining a good agreement with experiments. Finally, a numerical analysis of the impact of the chalcogenide thickness on the dispersion was performed, showing that the dispersion properties can be finely tuned with a reasonable chalcogenide thickness resolution of $\approx 100 \mathrm{~nm}$. These results introduce the deposition of a chalcogenide cladding layer as a simple post processing tool to trim the waveguide's group velocity dispersion depending on the actual structure produced by fabrication.

Agence Nationale de la Recherche (ANR) MIRSiCOMB (ANR-17-CE24-0028), European ERC grant GRAPHICS (648546); We acknowledge the support of the LIA ALPhFA

\section{References}

[1] R. Soref, Nature Phot., 4, 495-497, (2010).

[2] N. K. Hon, R. Soref and B. Jalali, J. Appl. Phys. 110, 011301 (2011).

[3] G. Z. Mashanovich et al., J. Light. Technol. 35, 624-630 (2017).

[4] M. Sinobad et al., Optica 5, 360 (2018).

[5] F. Lu, and W. H. Knox, J. Opt. Soc. Am. B 23(6), 1221-1227 (2006).

[6] G. Wong et al., Opt. Lett. 35(23), 3982-3984 (2010).

[7] J. Pan, et al., Appl. Phys. Lett. 92(10), 103114 (2008).

[8] F. Raineri, et al., Opt. Lett. 30(1), 64-66 (2005).

[9] C. Grillet, et al., Laser \& Photonics Rev. 4(2), 192-204 (2010).

[10] A. Casas Bedoya et al., Opt. Express 20(10), 11046-11056 (2012). 